\title{
Investigations on Preparation and Characterization of Certain Copolyesters
}

\author{
Kalpana Jayachandran ${ }^{a *}$, Ravichandran Cingaram ${ }^{b}$, Jaisankar Viswanathan $^{c}$, Suresh Sagadevan ${ }^{d}$ \\ and Venkatachalam Jayaraman \\ ${ }^{a}$ Department of Chemistry, Jawahar Engineering College, Chennai, India \\ ${ }^{b}$ Department of Chemistry, Easwari Engineering College - EEC, Chennai, India \\ ${ }^{c}$ Department of Chemistry, Presidency College, Chennai, India \\ ${ }^{d}$ Department of Physics, AMET University, Chennai, 603 112, India \\ ${ }^{e}$ Department of Physics, Meenakshi College of Engineering - MCE, Chennai, India
}

Received: September 24, 2015; Revised: November 21, 2015; Accepted: December 27, 2015

\begin{abstract}
In this paper, we report on the synthesis and characterization of high molecular weight copolyesters from Terephthalic acid, 1, 4 butane diol and Succinic acid /Sebacic acid through a two step process of melt polycondensation using titanium tetra butoxide as catalyst. The synthesized aromatic-aliphatic random copolyesters were characterized by means of FTIR, ${ }^{1} \mathrm{H}$ NMR, ${ }^{13} \mathrm{C}$ NMR, Differential Scanning Calorimetry (DSC), X-ray Diffraction (XRD), Gel Permeation Chromatography (GPC) and Scanning Electron Microscope (SEM) studies. The effect of copolymer composition on the physical and thermal properties as well as degradation test was investigated. The degradation test was carried out in alkali medium. The phase behaviour of the polymers was studied by differential scanning calorimetry and optical polarising microscopy. The results revealed that the newly synthesized copolyesters exhibited degradability and thermotropic liquid crystalline behaviour with nematic texture which was revealed by optical polarising microscopy. The Novelty of this work is that the glass transition temperature and melting temperature are above the room temperature for the synthesized polymers. This shows the good thermal stability which results in early processing of liquid crystalline materials.
\end{abstract}

Key words: Aliphatic - Aromatic copolyesters, Melt polycondensation, Degradation, Liquid crystalline

\section{INTRODUCTION}

Polymers have contributed tremendously to human life from simple household items to high technological applications. The amount of plastic wastes has increased all over the world, which threatens to cause a serious environmental problem and has become a matter of great concern to the people throughout the world including scientists from different countries. Some steps such as reducing the use of plastic products and recycling the plastic waste have been taken to solve this problem. One of the feasible ways is to develop biodegradable plastics ${ }^{1}$. Therefore, a series of biodegradable polymers were developed in the past decades, most of which were aliphatic polyesters, such as poly(lactic acid) (PLA), poly( $\varepsilon$-caprolactone) (PCL), poly(3-hydroxybutyrate) (PHB), poly(butylene succinate) (PBS), poly(propylene succinate) (PPSu), poly(propylene adipate) (PPAd), poly(ethylene succinate) (PES), and poly(propylene sebacate) (PPSe) ${ }^{2-7}$.

Much attention is being paid to aliphatic polyesters because of their degradability ${ }^{8,9}$. But the limitation of these polyesters is due to low thermal and mechanical properties. Copolymerization ${ }^{10,11}$ and blending ${ }^{12,13}$ with aromatic polyesters to modify the properties of aliphatic polyesters are better choices in both mechanical and thermal aspects. Meanwhile, a study shows that there is degradability for aromatic polyesters when they are copolymerised with aliphatic

*e-mail: kalpanachemistry2011@gmail.com

polyesters ${ }^{14}$. In recent years thermotropic liquid crystalline polyesters have received a great deal of attention ${ }^{15,16}$. Some interesting attempts were made in the 1980's to synthesize thermotropic random copolymers by introducing two different lengths of flexible spacers in the main-chain ${ }^{17,18}$. Liquid crystalline aliphatic-aromatic random copolyesters are becoming increasingly important as they are used as structural materials in various fields whose particular properties make them ideally suited to high precision mouldings, as well as for high performance fibres. Bearing in mind the high commercial potential of aliphatic-aromatic copolyesters and their interesting properties, the work focused on the synthesis and characterization of certain random aliphatic-aromatic copolyesters ${ }^{19}$. The structure of their repeating units and the effect of copolymer composition on the physical and thermal properties, optical polarising microscopic studies as well as degradation were investigated in alkali medium.

\section{MATERIALS AND METHOD}

\subsection{Materials}

Sebacic acid (Merck AR grade), Succinic acid (Lancaster AR grade) and Terephthalic acid (Lancaster AR grade) were recrystalised from deionised water and used. 1, 4 Butane diol (Lancaster AR grade) was dried with $\mathrm{CaO}$ overnight 
and distilled under reduced pressure. Titanium tetra butoxide $\left(\mathrm{Ti}(\mathrm{OBu})_{4}\right)$, used as catalyst, purchased from Lancaster was used as such. All the other materials and solvents used were of analytical grade.

\subsection{Synthesis of Copolyesters}

The copolyesters were synthesized by two step melt poly condensation method, because in this method, the chemical reaction is simple, non-toxic and less expensive compared with other synthetic methods. As an example, the synthesis of poly (butylene succinate -co- butylene Terephthalate) PBSBT is described. The polycondensation flask is a three neck flask equipped with a condenser, nitrogen inlet and a thermometer. To stir the reaction mixture a magnetic stirrer was used. The reaction mixture consists of 1, 4 Butane diol, Succinic acid (Lancaster AR grade) and Terephthalic acid taken in the ratio $2: 1: 1$, which means 2 moles of reactant react with each one mole of diacids to give a linear polyester. The reaction mixture was purified with nitrogen and heated in an oil bath. The purpose of using nitrogen gas is to maintain inert atmosphere. Due to this, degree of polymerization increases; so does the molecular weight. The temperature of the reaction mixture was raised to $150^{\circ} \mathrm{C}$ in $20 \mathrm{~min}$. Then the temperature was gradually raised in steps of $10^{\circ} \mathrm{C}$ every minute to the reaction temperature of $210^{\circ} \mathrm{C}$ to remove water being the esterification by product as there is a possibility of decomposition of monomers which leads to decrease in yield. When water ceased to be generated, a predetermined amount of titanium tetra butoxide $\left(\mathrm{Ti}(\mathrm{OBu})_{4}\right)(0.1 \mathrm{mmol})$ catalyst was added to the reaction mixture. Subsequently, the pressure of the reaction system was lower than $0.5 \mathrm{mmHg}$. The reaction was terminated when the mechanical stirrer stopped rotating. The resulting mixture was crude copolymers and dissolved in chloroform as the synthesized polymer shows more solubility in polar solvents such as chloroform and hence used as solvent. Then it was poured into excess of dry cold methanol to purify the polyester. The precipitated copolyesters were dried in a dessicator and used for further characterization.

\section{Characterization Methods}

Chemical structure of pure copolyesters synthesized was investigated by FTIR measurements which were performed using KBr pelleted samples with a Perkins Elmer 200 FTIR spectrophotometer with a resolution of $4 \mathrm{~cm}^{-1}$ in the range of $400-4000 \mathrm{~cm}^{-1} .{ }^{1} \mathrm{H}$ NMR spectra were recorded on AV $3500 \mathrm{MHz}$ Spectrometer by using $7 \%$ wt of $\mathrm{CDCl}_{3}$ mixed solvent. ${ }^{13} \mathrm{C}$ NMR spectra were recorded at $300-600 \mathrm{MHz}$ in deuterated chloroform as solvent. The DSC scans were recorded at a heating rate of $10^{\circ} \mathrm{c} / \mathrm{min}$ using Perkin-Elmer Pyris I analyzer. Indium was used as the calibration standard. A Siemens D 500 diffractometer with $\mathrm{CuK}_{\alpha}$ filter radiation was used for assessing crystallinity of the polymers. The samples were scanned over the range of $2 \theta$ angle, from $10^{\circ}$ to $90^{\circ}$. The morphology of the polyester film was investigated by Scanning Electron Microscope before and after degradation by keeping in $0.1 \mathrm{~N} \mathrm{NaOH}$ solution at regular time intervals. Tetrahydrofuran was used as eluent. Polystyrene standard was used for calibration with a flow rate of $1 \mathrm{ml} / \mathrm{min}$. Concentration of the mobile phase was $0.005 \mathrm{~g} / 5 \mathrm{ml}$. The optical texture of the melts was examined on a hot stage (Mettler FP-5) attached to a polarizing microscope.

\section{Results and Discussion}

\subsection{Fourier-Transform Infrared (FTIR) Spectroscopy}

FTIR spectra of copolymers derived from PBSBT and PBSeBT are shown in Figure (1a\&1b. Band characteristics of aromatic esters were observed between $1719.45 \mathrm{~cm}^{-1}$ and $1717.59 \mathrm{~cm}^{-1}(\mathrm{C}=\mathrm{O}$ stretching $)$ and between $730.84 \mathrm{~cm}^{-1}$ and $727.96 \mathrm{~cm}^{-1}$ (ring $\mathrm{C}-\mathrm{H}$ out of plane bending). The $\mathrm{C}-\mathrm{H}$ symmetric stretching of aliphatic- $\mathrm{CH}_{2}$ - group was observed at 2953.49-2930.39 $\mathrm{cm}^{-1}$. Strong vibrational modes observed at $1164.59 \cdot 1171.59 \mathrm{~cm}^{-1}$ were associated with $\mathrm{C}=\mathrm{O}$ stretching modes of esters.

\section{2. ${ }^{1} H$ NMR spectral data of random copolyester}

NMR is used to study the structure of repeating units and nature of proton present in the polymer chain. The chemical shift values observed from $1 \mathrm{H}$ NMR spectra of the copolyesters of PBSBT and PBSeBT are as follows: A singlet at $\delta=8.1-8.06 \mathrm{ppm}$ was due to aromatic protons of Terephthalic group, multiplet at $\delta=4.02-4.05 \mathrm{ppm}$ was due to the protons of $-\mathrm{CO}-\mathrm{OCH}_{2}-$ group, and multiplet at $\delta=1.48-1.34$ ppm was due to methylene protons of 1,4 butane diol (Figs.2a \& 2b).

\section{3. ${ }^{13} \mathrm{C}$ NMR spectral data of random copolyester}

The chemical shift values obtained from ${ }^{13} \mathrm{C}$ NMR Spectra of the copolyesters PBSBT and PBSeBT are as follows: A singlet at $\delta=133.97-134.07 \mathrm{ppm}$ was due to quartenary carbon atoms of terephthalate. A doublet at $\delta=172.30-173.84 \mathrm{ppm}$ was due to carbonyl carbon atom
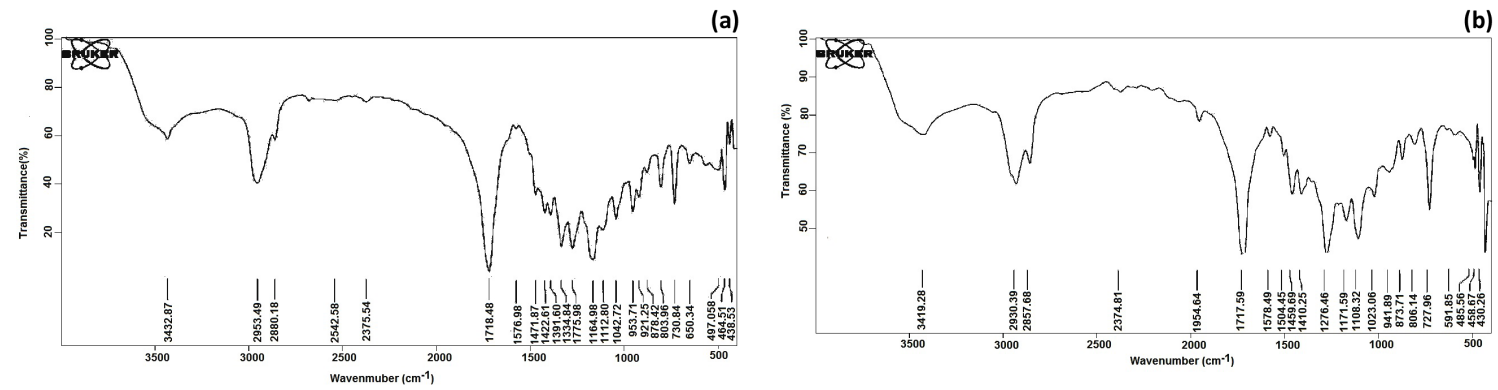

Fig. 1 a. FTIR of PBSBT copolyester; b. FTIR of PBSeBT copolyester 
of the ester group and multiplet at $\delta=64.56-63.73 \mathrm{ppm}$ was due to $-\mathrm{CH}_{2}-\mathrm{CO}$ - group (Figs.3a\&3b).

\subsection{Differential Scanning Calorimetry (DSC)}

DSC analysis was used to find the glass transition temperature $\left(\mathrm{T}_{\mathrm{g}}\right)$ of synthesized polymers are shown in Figs $4 \mathrm{a} \& 4 \mathrm{~b}$. Glass transition temperature of any polymer is the temperature at which it becomes soft and rubbery in nature on heating. That is to say, the temperature above which it is hard and glass and below which it is rubbery is called the glass transition temperature $\left(\mathrm{T}_{\mathrm{g}}\right)$.

From the above Table 1 it is clear that glass transistion temp $\left(\mathrm{T}_{\mathrm{g}}\right)$, Melting temperature $\left(\mathrm{T}_{\mathrm{m}}\right)$ Decomposition temperature $\left(\mathrm{T}_{\mathrm{d}}\right)$ and heat of fusion $\Delta \mathrm{Hm}$ increase with increase in chain length of polyesters. The glass transition temperature $\left(\mathrm{T}_{\mathrm{g}}\right)$ of polyester is closely related to the flexibility of the chain. Due to high barrier of bond rotations $T_{g}$ value is high for PBSeBT.

(a)
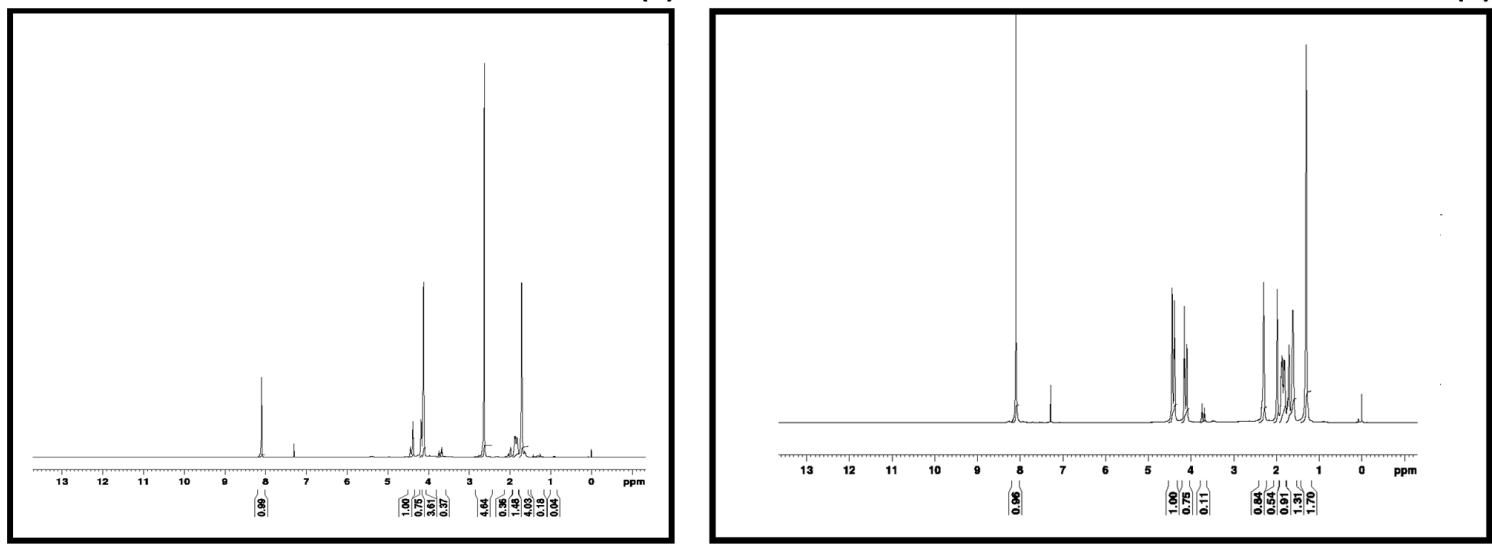

Fig.2 a. ${ }^{1} \mathrm{H}$ NMR of PBSBT copolyester; b. ${ }^{1} \mathrm{H}$ NMR of PBSeBT copolyester

(a)

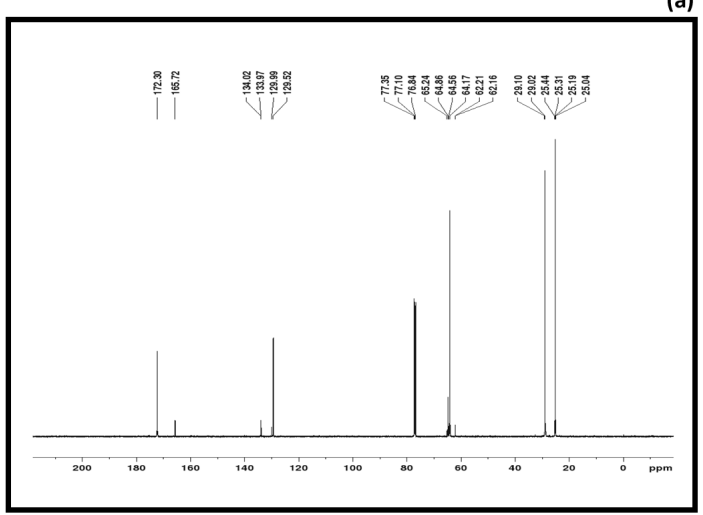

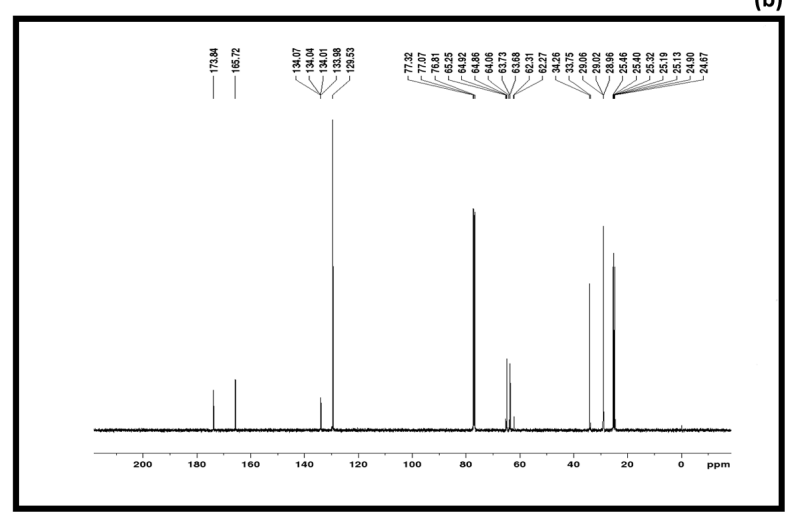

Fig.3a. ${ }^{13} \mathrm{C}$ NMR of PBSBT copolyester; b. ${ }^{13} \mathrm{C}$ NMR of PBSeBT copolyester

(a)

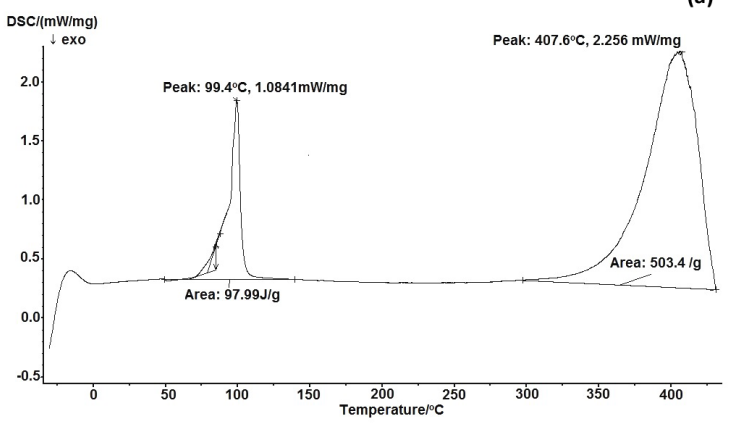

(b)

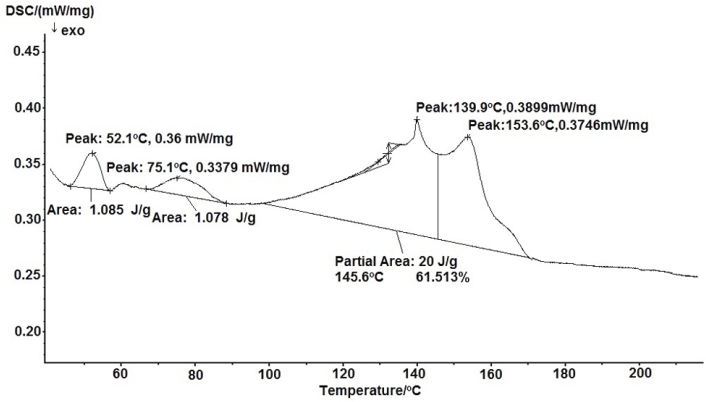

Fig.4a. DSC Thermogram of PBSBT copolyester; b. DSC Thermogram of PBSeBT copolyester 


\section{$4.5 X$ - ray Diffraction Analysis}

X-ray diffractogram of the synthesized polymers are shown in Figs 5a \&5b. Gaussian curves are used to describe the amorphous phase and crystal reflections of diffractogram ${ }^{20,21}$. The diffractograms reveal that the degree of crystallinity is higher for PBSBT than for PBSeBT which is supported by increase in the melting point obtained from DSC measurements for polymers. This indicates that the crystallinity of the polyester decreases with the increase in the length of flexible segments. Thus, PBSeBT was found to have low crystallinity and the value obtained is tabulated as shown in Table.2. The percentage crystallinity of copolyester was calculated by Debye Scherre's equation.

\subsection{Scanning Electron Microscopy (SEM)}

The surface morphology of the copolyester was examined through scanning electron microscope (SEM) and the weight loss due to degradation is shown in Table.3. The SEM images in Figs. $6 \mathrm{a} \& 6 \mathrm{~b}$ show rough surface with cavities on the

Table.1: Thermal properties of the synthesized copolyesters

\begin{tabular}{crrrr}
\hline Co-polyester & $\mathbf{T}_{\mathbf{g}}\left({ }^{\circ} \mathbf{C}\right)$ & $\mathbf{T}_{\mathbf{m}}\left({ }^{\circ} \mathbf{C}\right)$ & $\mathbf{T}_{\mathbf{d}}\left({ }^{\circ} \mathbf{C}\right)$ & $\begin{array}{c}\Delta \mathbf{H m} \\
(\mathbf{J} / \mathbf{g})\end{array}$ \\
\hline PBSBT & 78.8 & 84.7 & 90.6 & 1.389 \\
PBSeBT & 125.6 & 132.2 & 135.3 & 0.106 \\
\hline
\end{tabular}

Table.2: XRD parameters of PBSBT and PBSeBT copolyester

\begin{tabular}{ccrccc}
\hline Poly ester & $\begin{array}{c}\text { Pos. } \\
{\left[{ }^{\circ} \mathbf{2 T h} \text {.] }\right.}\end{array}$ & $\begin{array}{c}\text { Height } \\
{[\text { [cts] }}\end{array}$ & $\begin{array}{c}\text { FWHM } \\
\text { Left } \\
{\left[{ }^{\circ} \text { 2Th.] }\right.}\end{array}$ & $\begin{array}{c}\text { d-spacing } \\
{[\AA]}\end{array}$ & $\begin{array}{c}\text { Rel. } \\
\text { Int. } \\
{[\%]}\end{array}$ \\
\hline PBSBT & 23.1784 & 259.68 & 0.6888 & 3.83755 & 100.00 \\
PBSeBT & 23.4748 & 26.48 & 0.7200 & 3.78662 & 100.00 \\
\hline
\end{tabular}

film which is ample evidence for the degradation property for the synthesized copolyesters.

Thus it is clear from the above Table that the rate of degradation in alkaline medium decreases with increase in the chain length of the copolyester. Percentage of weight loss is calculated with time and is graphically represented below as shown in Fig.7.

\subsection{Gel Permeation chromatoghraphy (GPC)}

Gel permeation chromatography has its greatest value for measuring the molecular weight and polydispersity of synthetic polymers. This method depends on distribution coefficients, relating the selective distribution of an analysis between the mobile phase and stationary phase. It gives an idea of number average and weight average molecular weight. If molecular weight is more, processability is early. The chromatograms in Figs. $8 \mathrm{a} \& \mathrm{~b}$ show $\mathrm{Mn}$, Mw values which are tabulated in Table.4.

\subsection{Optical Polarized Microscopy (OPM)}

Thermotropic liquid crystalline polyesters with low $\mathrm{T}_{\mathrm{g}}$ values followed by a sharp transistion to a mesophase with as low $\mathrm{T}_{\mathrm{m}}$ value as possible are attracting current interest due to their use in reprographic appllications. The widely employed technique to identify the mesophases in thermotropic liquid crystalline polymers is OPM studies.

OPM and DSC were used to determine the mesogenic transistion temperature $\left(\mathrm{T}_{\mathrm{m}}\right)$ as well as the mesophase to the isotropic transition temperature $\left(\mathrm{T}_{\mathrm{i}}\right)$. From Table.5, it is observed that the incorporation of the spacers and increasing their length result in increase in the range of mesophase temperatures. The texture examination has become a very useful tool in the determination of the type and nature of the polymeric liquid crystals. OPMs of the synthesized
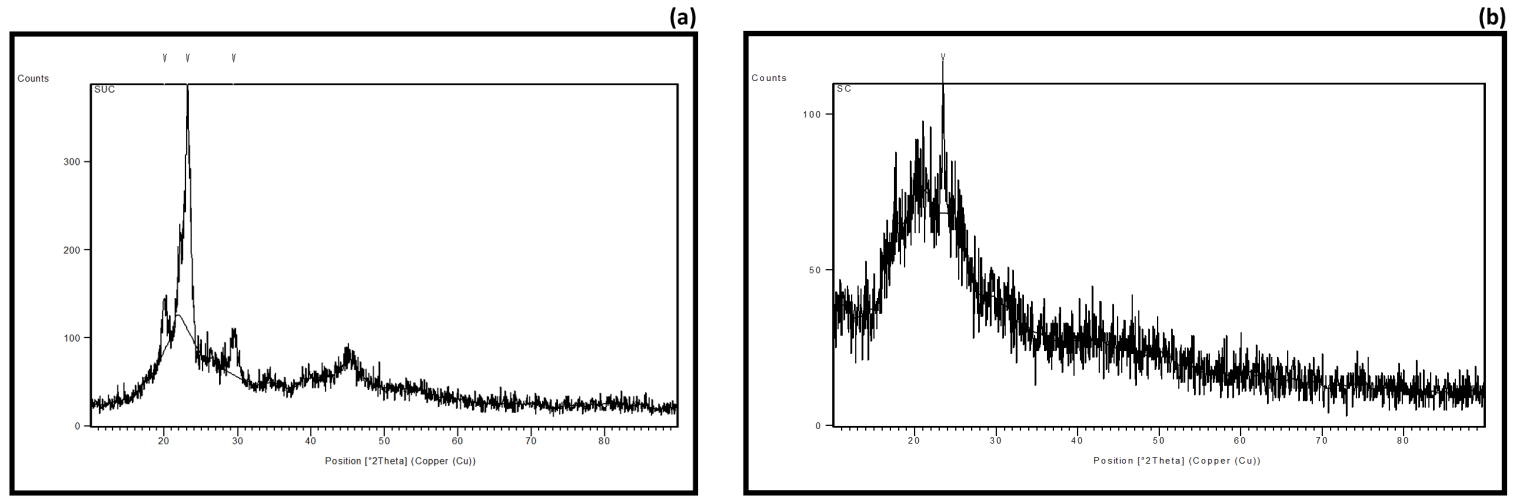

Fig.5a. X-Ray Thermogram of PBSBT copolyester; b. X-Ray Thermogram of PBSeBT copolyester
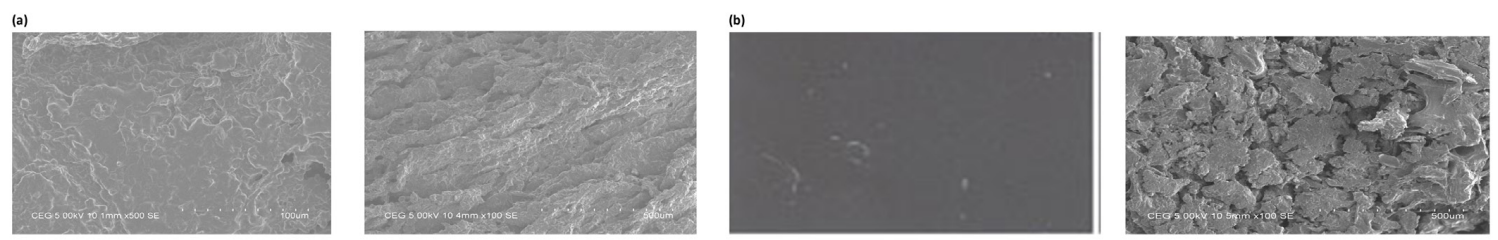

Fig.6a. SEM Micrographs of PBSBT before and after alkaline $(0.1 \mathrm{~N} \mathrm{NaOH})$ degradation; b. SEM Micrographs of PBSeBT before and after alkaline $(0.1 \mathrm{~N} \mathrm{NaOH})$ degradation 
Table.3: Weight loss of copolyester in $(0.1 \mathrm{~N} \mathrm{NaOH})$ alkaline test

\begin{tabular}{cccccccc}
\hline & $\begin{array}{c}\text { Initial weight } \\
(\mathbf{g})\end{array}$ & $\begin{array}{c}\text { After 24 } \\
\text { hours(g) }\end{array}$ & $\begin{array}{c}\text { After 48 } \\
\text { hours (g) }\end{array}$ & $\begin{array}{c}\text { After 72 } \\
\text { hours (g) }\end{array}$ & $\begin{array}{c}\text { After 96 } \\
\text { hours (g) }\end{array}$ & $\begin{array}{c}\text { After 120 } \\
\text { hours (g) }\end{array}$ & $\begin{array}{c}\text { After 144 } \\
\text { hours (g) }\end{array}$ \\
\hline $\begin{array}{c}\text { PBSBT } \\
\text { copolyester }\end{array}$ & 1.512 & 1.323 & 1.015 & 0.902 & 0.852 & 0.789 & 0.752 \\
\hline $\begin{array}{c}\text { PBSeBT } \\
\text { Copolyester }\end{array}$ & 1.511 & 1.112 & 0.981 & 0.844 & 0.798 & 0.698 & 0.658 \\
\hline
\end{tabular}

Table.4: Thermal transition temperatures of the synthesized polyesters

\begin{tabular}{cccccc}
\hline S.No & Polyesters & Mn g/mol & Mw g/mol & $\begin{array}{c}\text { Polydispersity Degree of } \\
\text { inh(dL/g) Index(Mw/Mn) }\end{array}$ & $\begin{array}{c}\text { Degree of } \\
\text { polymeristion }\end{array}$ \\
\hline 1 & PBSBT & 6275 & 8490 & 1.32 & 22.32 \\
2 & PBSeBT & 7052 & 9348 & 0.94 & 22.14 \\
\hline
\end{tabular}

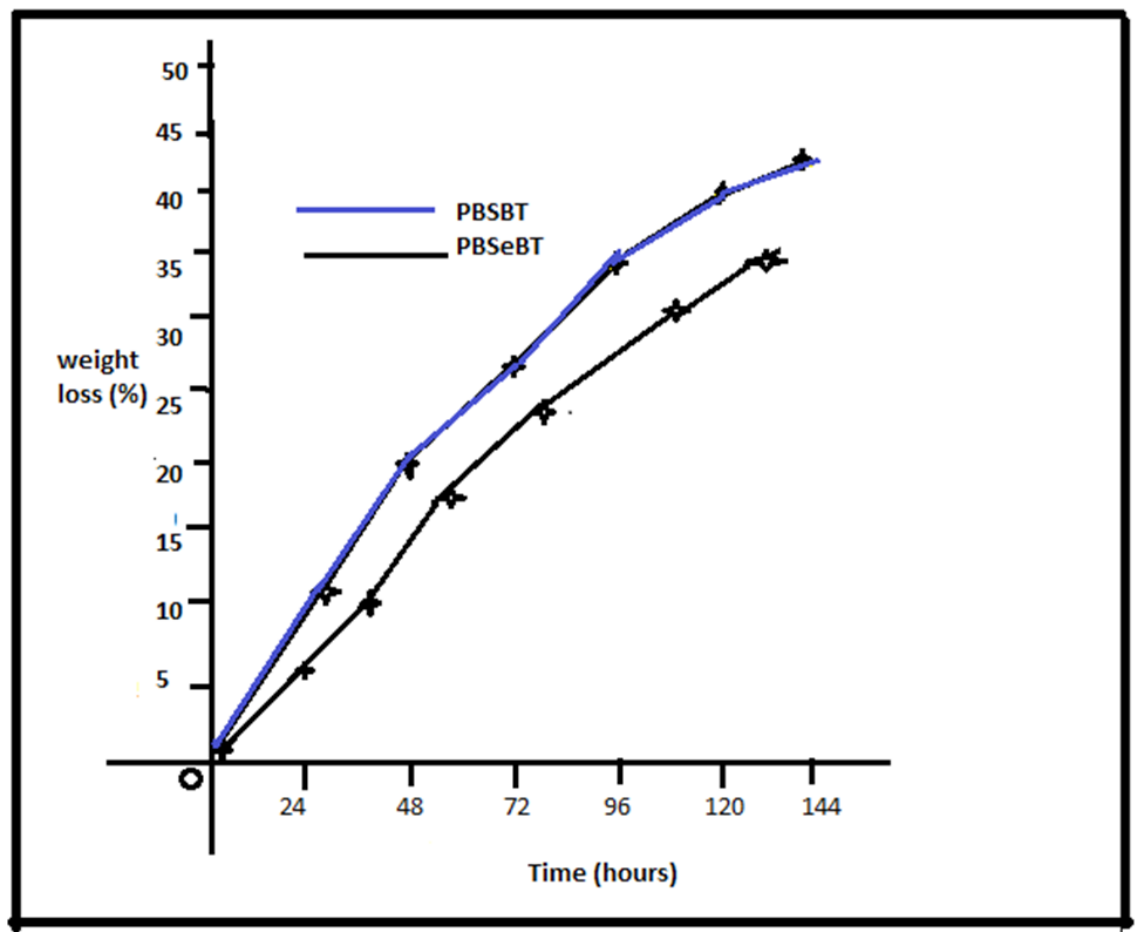

Fig.7 Alkali degradation of copolyester, PBSeBT and PBSBT

(a)

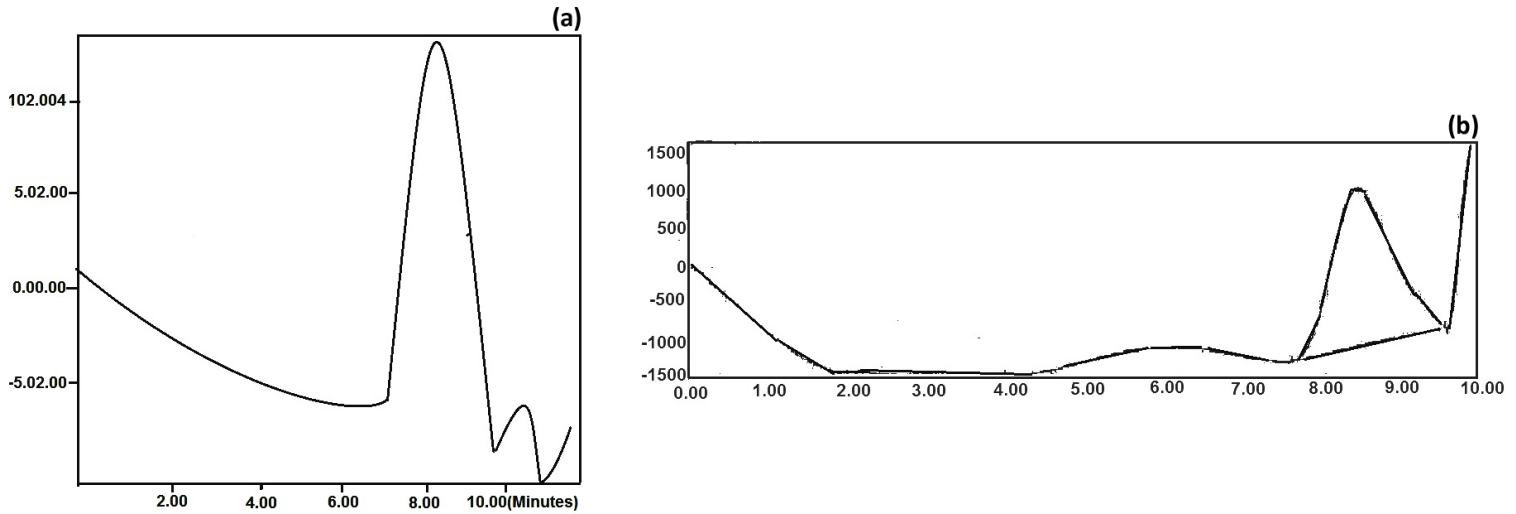

Fig.8a. GPC Thermogram of PBSeBT copolyester; b. GPC Thermogram of PBSBT copolyester 


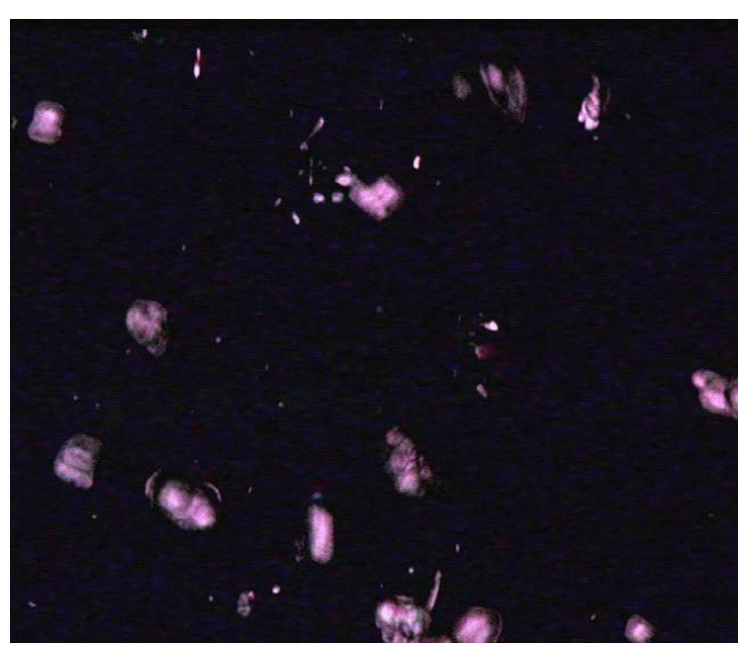

Fig.9 OPM of PBSeBT at $1580 \mathrm{C}$

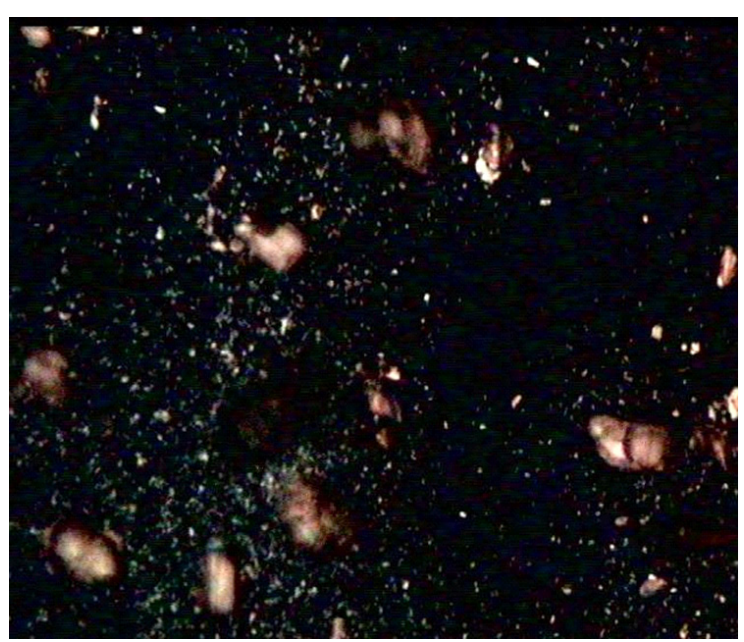

Fig.10 OPM of PBSBT at 124.50C

\section{REFERENCES}

1. Rizzarelli P, Puglisi C, Montaudo G . Soil burial and enzymatic degradation in solution of aliphatic co-polyesters. Polymer Degradation and Stability. 2004;85(2):855-863.

2. Anderson JM. Recent advances in biomedical polyurethane biostability and biodegradation. Polymer International. 1998;46:163-171

3. Decker C, Bendaikha T. Interpenetrating polymer networks. II. Sunlight-induced polymerization of multifunctional acrylates. Journal of Applied Polymer Science. 1998; 70(11):2269-2282.

4. Umare SS, Chandure AS, Pandey RA. Synthesis, characterization and biodegradable studies of 1,3-propanediol based polyesters. Polymer Degradation and Stability. 2007;92(3): 464-479.

5. Papageorgiou GZ, Bikiaris DN. Crystallization and melting behavior of three biodegradable poly(alkylene succinates). A comparative study. Polymer. 2005;46:12081-12092.

6. Kim JK, Park DJ, Lee MS, Ihn KJ. Synthesis and crystallization behavior of poly(L-lactide) block-poly (e-Caprolactone) copolymer. Journal of Polymer, 2001;42(17):7429-7441.
Table.5. Thermal properties of the synthesized copolyesters

\begin{tabular}{cccccc}
\hline S.No & Copolyesters & $\mathbf{T m}\left({ }^{\circ} \mathbf{C}\right)$ & $\mathbf{T i}\left({ }^{\circ} \mathbf{C}\right)$ & $\Delta \mathbf{T}\left({ }^{\circ} \mathbf{C}\right)$ & $\begin{array}{c}\text { Types of } \\
\text { mesophase }\end{array}$ \\
\hline 1 & PBSBT & 135.0 & 146 & 12 & Nematic \\
2 & PBSeBT & 102.0 & 122 & 20 & Nematic \\
\hline
\end{tabular}

copolyesters in Figs. 9 \& 10 show a characterization of liquid crystals by polarized light microscopy which is most useful for polymers possessing desired mechanical, thermal and optical properties ${ }^{22-24}$. Nematic texture was observed in the heating as well as the cooling cycles in OPM. Hence, these copolyesters are commonly termed liquid crystalline glasses.

\section{CONCLUSION}

The Aliphatic-aromatic random Liquid crystalline biodegradable Copolyesters were synthesized from sebacic acid/ succinic acid, Terephthalic acid and 1,4-butanediol by a two-step melt polycondensation, transesterification in the bulk using Titanium tetra butoxide as catalyst at $210^{\circ} \mathrm{C}$ under reduced pressure. IR and NMR spectral data were in agreement with the functional group and nature of mesogens present. Thermal methods of analysis (DSC) helped determine the glass transition temperature, melting temperature, and decomposition temperature of the copolyesters. The biodegradation of these polyesters was carried out in alkali medium using the $0.1 \mathrm{~N}$ $\mathrm{NaOH}$. The results clearly indicated that the length of the polymer chains would be the major controlling factor on the biodegradability of polyesters. The highest degradation rate in alkali medium was observed for PBSeBT, which could be due to its lower crystallinity and melting temperature. Thus, the degradation of polyesters was influenced by the polyester composition, polyester properties such as molecular weight, melting temperature, crystallinity, and the glass transition temperature. Thermotropic liquid crystalline copolyesters synthesized in the present study showed nematic texture. So the synthesized copolyesters are commonly known as liquid crystalline glasses and this kind of polyester can also be used in biomedical field.

7. Piao LH, Dai Zl, Deng MX, Chen XS, Jing XB. Synthesis and characterization of PCL/PEG/PCL triblock copolymers by using calcium catalyst. Polymer. 2003;44:2025-2031.

8. Plikk P, Odelius K, Hakkarainen M, Albertsson AC. Finalizing the properties of porous scaffolds of aliphatic polyesters through radiation sterilization. Biomaterials. 2006;27:5335-5347.

9. Amass W, Amass A, Tighe B. A review of biodegradable polymers: uses, current developments in the synthesis and characterization of biodegradable polyesters, blends of biodegradable polymers and recent advances in biodegradation studies. Polymer International. 1998;47(2):89-144.

10. Zagar E, Krzan A, Adamus G, Kowalczuk M. Sequence distribution in microbial poly(3-hydroxybutyrate-co-3-hydroxyvalerate) copolyesters determined by NMR and MS. Biomacromolecules. 2006;7(7): 2210-2216.

11. Gonasalves KE, Chen X, Cameron JA. Degradation of nonalternating poly(ester amides).Macromolecules. 1992;25(12): 3309-3312. DOI: 10.1021/ma00038a047

12. Yoshie N. Crystallization and compatibility of poly(vinyl alcohol)/poly(3-hydroxybutyrate) blends: Influence of blend 
composition and tacticity of poly(vinyl alcohol), Journal of Applied Polymer Science. 1995;56(1): 17-24. DOI: 10.1002/ app.1995.070560103

13. Lim KY, Kim BC, Yoon KJ. Structural and physical properties of biodegradable copolyesters from poly(ethylene terephthalate) and polycaprolactone blends. Journal of Applied Polymer Science. 2003;88:131-138. DOI: 10.1002/app.11597

14. Tokiwa Y, Suzoki T. Journal of Applied Polymer Science. 1981;26: 441.

15. Cifferi A, Krigbaum WR, Meyer RB. Polymer liquid crystals. New York: Academic press; 1982.

16. Jin JI, Chang JH, Jo BW, Sung KY, Kang CS. Makromol. Sequentially ordered, thermotropic aromatic copolyesters: Synthesis and comparison of their properties with random copolyesters. Makromolekulare Chemie. 1990;33(1):97-115. DOI: 10.1002/masy.19900330109

17. Watanabe J, Krigbaum WR. Crystalline and liquid crystal transitions of mesogenic polymer mixtures and random copolymers. Macromolecules. 1984;17(11):2288-2295. DOI: 10.1021/ma00141a017

18. Percec V, Nava, H, Jonsson, H. Functional polymers and sequential copolymers by phase transfer catalysis. 24 . The influence of molecular weight on the thermotropic properties of a random copolyether based on 1,5-dibromopentane, 1,7-dibromoheptane, and 4,4'-dihydroxy- $\alpha$-methylstilbene.
Journal of Polymer Science. Part A. 1987; 25:1943-‘965, DOI: 10.1002/pola.1987.080250716

19. Indra R, Tamizharuvi T, Jaisankar V. Synthesis and characterization of certain biodegradable thermotropic liquid crystalline random copolyesters. Oriental Journal of Chemistry. 2012;28(3):14791487. DOI: $10.13005 / \mathrm{ojc} / 280353$

20. Fernandez-Blázquez JP, Bello A, Pérez E. Observation of two glass transitions in a thermotropic liquid-crystalline polymer. Macromolecules. 2004;37(24):9018-9026. DOI: 10.1021/ ma049354r

21. Wang ZG, Hsiao BS, Fu BX, Liu L. Correct determination of crystal lamellar thickness in semicrystalline poly(ethylene terephthalate) by small-angle X-ray scattering. Polymer. 2000;41(5): 1791-1797. DOI: 10.1016/S0032-3861(99)00327-4

22. Scott G, Gilead D, editors. Degradable polymers: principles and applications. London: Chapman \& Hall; 1995.

23. Cassidy PE. Thermally stable polymers. New York; Marcelo Dekker; 1980.

24. Shen Z, Chen X, Shen Y, Zhang Y. Ring-opening polymerization of e-caprolactone by rare earth coordination catalysts. I. Characteristics, kinetics and mechanism of e-caprolactone polymerization with nd (aca) $3 \mathrm{H}_{2} \mathrm{O}-\mathrm{ALET}_{3}$ system. Journal of Polymer Science Part A. 1994;32(4):597-603. DOI: 10.1002/ pola.1994.080320401 